\title{
EXPERIMENTAL EVIDENCE CONCERNING THE DETERMINATION OF POSTURE OF THE MEMBRANOUS LABYRINTH IN AMPHIBIAN EMBRYOS
}

\author{
GEORGE L. STREETER \\ Department of Anatomy, University of Michigan \\ THIRTY-EIGHT FIGURES
}

The purpose of the present paper is to report a series of experiments that substantiate the conclusion that the posture of the membranous labyrinth and the position of its canals is determined by some force or influence that interacts between the labyrinth and its environment. The exact nature of this control or influence has not yet been determined, but from the experiments that are to be described it is evident that it possesses a force capable of producing a complete rotation of an embryonic vesicle that has been displaced in a reversed position.

The existence of a postural influence of this kind introduces a new factor in organogenesis. It means that organs do not develop inertly in the position that they happen to find themselves; on the contrary, there is a certain amount of adjustment of position through forces interacting between them. According to the conception of what we might call the theory of passive organ development, all organs develop passively in the position in which they are located at the outset. Perfect form according to this theory is eventually obtained because originally the anlages of the various organs are so perfectly placed, and all the stresses so carefully calculated, that the subsequent increase in size, and mutual pressure against each other, produce a final normal disposition of all of them. In contrast to this we may now speak of self-placement of organs or individuality of organ development, according to 
which there is, in addition to the passive pressures of adjacent structures, a motive element, the force of placement, which helps to maintain, and corrects if necessary, the relative position of an individual organ. This force of placement may be defined as the product of the combined motive forces interacting between an organ and its environment. We are already familiar with the striking phenomenon of muscle migration and the movement of nerve-ganglion masses. We can now add to this the potential movement and adjustment of entire organs during their course of development, and it is not necessary to add that this autostatic tendency is doubtless much more pronounced in some organs than in others.

The writer's attention was first directed to the possibility of experimentally altering the position of the developing labyrinth, during some investigations on equilibration in amphibian larvae (Streeter '06). In these experiments it was found that the cells constituting the ear vesicle are specialised very early, and though transplanted to an abnormal environment they continue to differentiate themselves in the usual way into a recognizable labyrinth. Lewis ('07) showed in a subsequent paper that this was true while they were still in the stage of an uninvaginated plate, quite in contrast to the surrounding cells forming the cartilaginous capsule, which Lewis clearly proved were not predetermined in this way.

In a later paper (Streeter '07) additional evidence was given of the high degree of developmental independence possessed by the early labyrinth cells. It was shown that even fragments of the vesicle may develop independently of the rest of the vesicle, and any individual part, for example the endolymphatic appendage, may be quite normal in cases where the remainder of the labyrinth is very abnormal. It was also shown (Streeter '09) that when two primitive vesicles are crowded together into the same pocket they do not fuse and form together one large labyrinth, but remain as two distinct labyrinths. Moreover, it was shown that this developmental independence of the vesicles extends to the difference existing between a right and left-sided organ. The dextral or sinistral character, or laterality of the ear 
vesicle, is not controlled by the environment but is determined by the intrinsic character of its own constituent cells. A left-sided ear vesicle when transplanted to the right side develops into a labyrinth having all the characteristics of a left-sided organ; the anterior canal is formed on the caudal border of the labyrinth, the posterior canal on the oral border, and the lagena, which normally is directed caudalward, is found extending forward toward the eye.

It was found, however, that the ear vesicle, though capable of this marked power of self-differentiation, apparently was not in all respects independent of the surrounding structures. The pusture of the developed labyrinth, the situation of its canals and various chambers, seemed to be controlled by the environment. Deliberate rotation of the ear vesicle into abnormal positions and even transplantation to the opposite side of the body, always resulted in a labyrinth possessing a normal attitude with reference to the brain, ganglion masses, and the surface of the body. In all of seventeen experiments performed for this purpose the results were positive, and the writer consequently came to the conclusion that there is some influence interacting between the ear vesicle and its environment that constitutes the chief factor in the determination of its placement.

At the same time an experienced foreign investigator had been working independently upon a similar problem (Spemann '06 a and ' $06 \mathrm{~b}$ ). His experiments consisted in removing the ear vesicle in young Rana esculenta larvae and then replacing it in an inverted position for the purpose of studying the consequent abnormal body movements and their correlation with the anatomical results of the operation. He also studied the influence of the epithelial labyrinth upon the surrounding connective tissue, and its relation to the formation of the cartilaginous and bony labyrinth. Concerning this latter problem he did not come to a definite conclusion. The former problem, however, gave positive results. He found that the inverted vesicle continued in its development and formed a more or less complete labyrinth, but, unlike my specimens, the orientation of the developed labyrinth corresponded to the operative displacement of the vesicle. There had been no subsequent readjustment of position. After the appearance of 
my papers (Streeter '06 and '07) in which I reported the experiments in which, after various displacements, the labyrinths all recovered their normal postural relations, Spemann ('10) made further experiments and reported more at length with regard to postural development. His results confirmed his earlier observations, and his paper contained illustrations showing sections of larvae of different ages in which the inverted ear vesicle has remained inverted though otherwise practically normal. Out of twelve operations nine labyrinths remained in ${ }^{-3 r t e d, ~ t w o ~ r e-~}$ covered partly, and one recovered perfectly the normal position. Regarding the latter specimen he surmised that it had not been sufficiently turned, and had slipped back into its normal position. The results, therefore, as obtained by Spemann are directly contradictory to those obtained by me. On account of the great embryological significance of the question of environmental postural control, further experiments were plainly warranted both for the purpose of testing my own previous results and if possible for finding some explanation of the discrepancy existing between the observations of Spemann and myself. From the study of these new experiments and from an examination of the accompanying photographs it will be plainly apparent that they confirm my previous results. Before entering into a further discussion of them we may proceed with a description of the details of the experiments themselves.

\section{METHOD OF OPERATION}

Obviously the conditions of the operation should be planned so that the environmental control would be put to an extreme test. In most of my previous experiments, and in all of Spemann's, the vesicle operated upon, after being taken out and rotated one way or another, was replaced in its own pocket. Recovery of the original posture after such an operation might be explained by the possibility of the vesicle not having been completely detached; some small strand of tissue might suffice to draw it back into the original position. Also it is conceivable that, since the vesicle and any adherent mesodermal fragment exactly fitted the pocket 
from which they were taken, they might on that account slip back into their original position. Both of these objections were avoided by transplanting a vesicle from one specimen into the emptied ear pocket of another specimen. This certainly involved complete detachment, and it is obvious that the transplanted ear vesicle would not exactly fit in a pocket in which it did not originally belong. All of the following experiments were done in that way.

The experiments were carried out on larvae of Rana pipiens, and the operating stage was the same as that used in previous experiments (Streeter '06, fig. 3, p. 547). This is just at the end of the non-motile stage, and the outer form of the larvae shows a distinct tail bud, and the eminences on the head caused by the optic cup and head ganglia. The ear consists of an invaginated saucershaped mass of cells just in the process of being pinched off from the deeper layer of the skin, with the edges inverted and in the process of completing the closure of the vesicle; that is, transition from auditory cup to auditory vesicle. In this, as in previous papers, the attempt is not made to distinguish between these two stages, and the term 'ear vesicle' is used to cover both. The technique of the operation is as follows: Two larvae are removed from their gelatinous capsules and placed side by side in distilled water, under a binocular microscope. With two no. 12 embroidery needles, a linear tranverse incision is made through the ectoderm of one of the specimens over the site of the ear vesicle, the incision being about three times as long as the vesicle, and the right side of the animal always being used for the operation. The lips of the wound are than gently everted, forward and backward respectively, which discloses the thin lateral wall of the vesicle, or if this is torn in the removal of the skin then one sees the pigmented concave interior of the vesicle. With the needles the vesicle is now loosened from its pocket and cast away. This leaves an empty pocket, free for the transplantation. The right vesicle of the second specimen is uncovered in a similar way, loosened from its pocket and then slipped into the empty right auditory pocket of the first specimen. In tucking in the vesicle under the edges of the wound care was taken in all cases to place the vesicle so that the lateral or concave open surface of 
the vesicle should lie against the brain, and the median or convex surface toward the opening of the wound. The lateral and median surfaces of the vesicle are easily recognized and therefore this transplantation in a reversed posture can be done with great accuracy. This method of placing the vesicle has a double advantage. It furnishes a complete rotation of 180 degrees and it is a secure way to transplant the vesicle which is very easily wedged in the pocket in that posture. The vesicle shows no tendency to escape, and as the lips of the wound are not very wide apart, it is not necessary to take any precautions about holding them together. They take care of themselves and need no superimposed weights or further attention. The specimen is now set aside and in the course of three or four hours all traces of the wound have disappeared. The specimens are allowed to go on with their development for fourteen days, the period usually necessary for the formation of the canals, at the end of which time they are preserved in a chrome-acetic mixture and are ready for examination. In most of the operations two specimens were utilized, one always being discarded after transplanting its right vesicle. In four experiments the writer succeeded in making a complete exchange of the right vesicle between the two specimens and preserving both of them. This involves great care and the additional effort required does not justify the procedure. The preserved specimens were imbedded in paraffin, cut in series and stained with hematoxylin and congo-red. Examination of them showed that nineteen of the experiments were successful, in that the transplanted vesicle had continued in its development far enough to recognize its different parts and their posture. Wax-plate models after the Born method were made of them all, and drawings of these, together with a photograph of a selected section from each series, are shown in figures 1 to 38. I may here state that these photographs were made with the apparatus belonging to my colleague, Professor Novy, and it gives me pleasure to take advantage of this opportunity to acknowledge his courtesy and his assistance in their preparation.

Other operations were performed with a view to the determination of character and degree of the environmental control, but these 
will not be reported on in this paper; we limit ourselves to the question of whether environmental control does or does not exist. It may be pointed out that the above operative procedure offers a complete and severe test for the existence of such control. It is so arranged that we have for the experiment a transplanted foreign ear vesicle, which does not naturally fit in its new pocket and which is intentionally placed in a posture as abnormal as possible.

\section{RESULTS OF THE EXPERIMENTS}

At the outset it may be stated that in all cases where the labyrinth had developed into a structure with sufficient completeness for the identification of its relations, it was found that the position of its canals and various chambers as regards the surrounding structures was practically normal, in spite of the manipulation it had undergone at the time of the operation. As has previously been shown (Streeter '07, p. 433) the posture of the labyrinth can be determined both by the histological structure of its walls and by its outer form, as determined by wax-plate reproductions. The description of these morphological characteristics will not be repeated here; it will be sufficient to state that they are so definite that the various parts of the labyrinth can be recognized without difficulty, even though they happen to be incomplete or unequally developed.

For the sake of compactness table 1 is annexed in which are detailed the separate features of each of the nineteen transplanted labyrinths as found on examination. Each feature is marked 'normal', 'imperfect,' or 'absent,' indicated by the signs $N, I$ and $O$. These are used in a liberal sense so, that 'normal' signifies practically normal, and includes structures abnormally large or small; 'imperfect' signifies quite abnormal, the characteristics, however, being sufficiently well defined for identification of the structure; and 'absent' means either completely absent or unrecognizable.

The features as listed will for the most part explain themselves. It may be mentioned, however, that by canal planes is meant the relative position of the canals as regards each other. Planes 
drawn through the anterior and posterior canals would meet at an angle of about 95 degrees at the crus commune. This is quite constant in all of the labyrinths. The lateral canal is about perpendicular to the other two. At the end of two weeks the planes are not so well defined as they are later, but when the canals are otherwise normal the planes can be determined, even as early as that.

From a study of this table it will be seen that we can arrange our experiments in three groups, based on the completeness of the

TABLE 1

\begin{tabular}{|c|c|c|c|c|c|c|c|c|c|c|c|c|c|}
\hline $\begin{array}{c}\text { LABYRINTH } \\
\text { NO. }\end{array}$ & \begin{tabular}{|c|c}
0 \\
0 \\
0 \\
0 \\
0 \\
0 \\
0 \\
0
\end{tabular} & 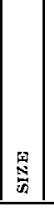 & 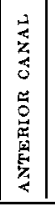 & 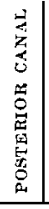 & 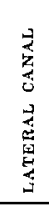 & 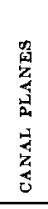 & 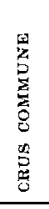 & 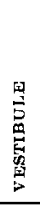 & 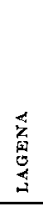 & 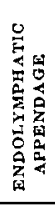 & 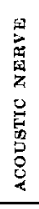 & 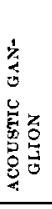 & 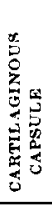 \\
\hline \multicolumn{14}{|c|}{ Normal group } \\
\hline $\mathrm{I}$ & $N$ & $\mathrm{~N}$ & $\mathrm{~N}$ & $\mathrm{~N}$ & $\mathrm{~N}$ & $\mathrm{~N}$ & $N$ & $\mathrm{~N}$ & $\mathrm{~N}$ & $\mathrm{~N}$ & $\mathrm{~N}$ & $N$ & $\mathrm{~N}$ \\
\hline II & $\mathrm{N}$ & $\mathrm{N}$ & $\mathrm{N}$ & $\mathrm{N}$ & $\mathrm{N}$ & $\mathrm{N}$ & $N$ & $\mathrm{~N}$ & $N$ & $\mathrm{~N}$ & $\mathrm{~N}$ & N & $N$ \\
\hline III & $\mathrm{N}$ & $\mathrm{N}$ & $\mathbf{N}$ & $\mathrm{N}$ & $\mathrm{N}$ & $\mathrm{N}$ & $\mathrm{N}$ & $\mathrm{N}$ & $\mathrm{N}$ & $\mathrm{N}$ & $\mathrm{N}$ & $\mathrm{N}$ & I \\
\hline IV & $\mathrm{N}$ & $\mathrm{N}$ & $\mathrm{N}$ & $\mathrm{N}$ & $\mathrm{N}$ & $\mathrm{N}$ & I & $\mathrm{N}$ & $\mathrm{N}$ & 0 & $\mathrm{~N}$ & $\mathrm{~N}$ & $\mathrm{~N}$ \\
\hline $\mathrm{V}$ & $\mathrm{N}$ & $\mathrm{N}$ & $\mathrm{N}$ & $\mathrm{N}$ & $\mathrm{N}$ & $\mathrm{N}$ & $\mathrm{N}$ & $N$ & $\mathrm{~N}$ & $\mathrm{~N}$ & $\mathrm{~N}$ & $\mathrm{~N}$ & I \\
\hline VI & $\mathrm{N}$ & $\mathrm{N}$ & $\mathrm{N}$ & $\mathrm{N}$ & $\mathrm{N}$ & $\mathrm{N}$ & $N$ & $\mathrm{~N}$ & $\mathrm{~N}$ & $\mathrm{~N}$ & $\mathrm{~N}$ & $\mathrm{~N}$ & $\mathrm{~N}$ \\
\hline VII & $\mathrm{N}$ & $\mathrm{N}$ & $\mathrm{N}$ & $\mathrm{N}$ & I & $\mathrm{N}$ & $\mathrm{N}$ & $\mathrm{N}$ & $\mathrm{O}$ & $\mathrm{N}$ & $\mathrm{N}$ & $\mathrm{N}$ & $\mathrm{N}$ \\
\hline VIII & $\mathrm{N}$ & $\mathrm{N}$ & $\mathrm{N}$ & I & $N$ & $N$ & I & N & $N$ & $\mathrm{~N}$ & $\mathrm{~N}$ & $\mathrm{~N}$ & $N$ \\
\hline \multicolumn{14}{|c|}{ Abnormal group } \\
\hline $\mathrm{IX}$ & $\mathbf{N}$ & $\mathrm{N}$ & $N$ & $\mathrm{~N}$ & I & $\mathrm{N}$ & $\mathrm{N}$ & I & $\mathrm{O}$ & $N$ & $\mathrm{~N}$ & $\mathrm{~N}$ & $N$ \\
\hline $\mathrm{x}$ & $\mathrm{N}$ & $\mathrm{N}$ & I & $\mathrm{N}$ & $\mathrm{N}$ & $\mathrm{N}$ & $\mathrm{N}$ & $\mathrm{N}$ & $\mathrm{N}$ & $\mathrm{O}$ & $\mathrm{N}$ & $\mathrm{N}$ & $N$ \\
\hline $\mathrm{XI}$ & $\mathrm{N}$ & I & $\mathrm{N}$ & $\mathrm{N}$ & I & $\mathrm{N}$ & $\mathrm{N}$ & $\mathrm{N}$ & $O$ & $\mathrm{~N}$ & I & I & $N$ \\
\hline XII & $\mathrm{N}$ & $\mathrm{N}$ & $\mathrm{N}$ & $\mathrm{N}$ & I & $N$ & $\mathrm{~N}$ & I & $O$ & $\mathrm{~N}$ & $N$ & $\mathrm{~N}$ & $N$ \\
\hline XIII & $\mathbf{N}$ & I & $\mathrm{N}$ & I & $\mathrm{N}$ & $\mathrm{N}$ & $\mathrm{N}$ & $\mathrm{N}$ & $\mathrm{O}$ & O & $\mathrm{N}$ & $\mathrm{N}$ & $\mathrm{N}$ \\
\hline XIV & $\mathrm{N}$ & I & I & I & $\mathrm{N}$ & $\mathrm{N}$ & I & $\mathrm{I}$ & $\mathrm{O}$ & O & $\mathrm{N}$ & $\mathrm{N}$ & $\mathrm{N}$ \\
\hline $\mathrm{XV}$ & I & $\mathrm{N}$ & I & $\mathrm{N}$ & I & $\mathrm{N}$ & I & $\mathrm{N}$ & 0 & $\mathrm{~N}$ & $\mathrm{~N}$ & $\mathrm{~N}$ & $\mathrm{~N}$ \\
\hline XVI & $\mathrm{N}$ & $\mathrm{N}$ & I & $\mathrm{I}$ & N & $\mathrm{N}$ & I & $\mathrm{N}$ & $\mathrm{N}$ & $\mathrm{N}$ & I & $N$ & $\mathrm{~N}$ \\
\hline \multicolumn{14}{|c|}{ Doubtful group } \\
\hline XVII & $\mathrm{N}$ & $\mathrm{N}$ & $\mathrm{N}$ & I & I & $\mathrm{N}$ & I & I & $\mathrm{O}$ & O & I & I & $N$ \\
\hline XVIII & $\mathrm{N}$ & $\mathrm{N}$ & $\mathrm{I}$ & I & $\mathrm{N}$ & I & I & I & $?$ & $\mathrm{O}$ & $\mathrm{N}$ & $\mathrm{N}$ & $\mathrm{N}$ \\
\hline XIX & $?$ & I & 0 & 0 & $?$ & $?$ & $?$ & $?$ & $\mathrm{~N}$ & 0 & 0 & 0 & $\mathrm{~N}$ \\
\hline
\end{tabular}


resultant development of the transplanted labyrinth. These are: firstly, those in which the labyrinth is nearly normal; secondly, those in which the labyrinth is abnormal though the main parts of it are easily recognizable; and thirdly, those in which there might be some question as to the identification of the different parts of the labyrinth. There are eight in the first group, eight in the second group, and three in the last group. Based on their order in these groups we may now proceed to the examination of the individual labyrinths.

Labyrinth I: (figures 1 and 2). The photograph shown in figure 1 is taken from Series X 2 C, slide 5, row 3, section 7. The study of this labyrinth shows only one slight departure from the normal, and that concerns the Saccus endolymphaticus which lies somewhat cephalad to the crus commune. It is on this account that it does not show in figure 1, which is directly through the crus. What looks as though it might be the edge of the sac, is the pigment layer of the skin. Aside from its slight anterior displacement it bears the usual relation to the chorioidal roof of the fourth ventricle and is normal in size.

Labyrinth II: (figures 3 and 4). Figure 3 is taken from Series $\mathrm{X} 2 \mathrm{~A}$, slide 4, row 1 , section 3 . Here as in Labyrinth $\mathrm{I}$ the endolymphatic sac is slightly in front of the crus commune. The crus is a little wider than in the former, so both it and the sac can be seen in figure 3. This labyrinth shows no noteworthy departure from the normal in either its histology or general form, aside from the slight displacement of the endolymphatic sac. In the drawing of figure 4 the groove between the ampullae of the anterior and lateral canals has been exaggerated a little more than is warranted by the reconstruction. In figure 3 the thickening of the ventro-lateral labyrinth wall is partly due to the crista of the lateral canal which it represents, and partly is due to the obliquity of the section of the ampulla. The characteristic relation of the endolymphatic sac to the chorioidal roof of the ventricle can be seen. The large ganglion on the ventro-median wall of the labyrinth is the proötic ganglion; the acoustic ganglion lies in a similar position but is found in the more caudal sections. Some of 
the acoustic root fibers, however, can be seen entering the side wall of the brain near the endolymphatic duct.

Labyrinth III: (figures 5 and 6 ). Figure 5 is taken from Series $X 7 \mathrm{~A}$, slide 4, row 2 , section 4 . In the reconstruction of this labyrinth there is apparently nothing abnormal. And on examination of the section the only departure from the normal is a slight deficiency in the cartilaginous capsule in the region of the lateral center. The parabasal plate seems normal. The ganglion shown in figure 5 is the proötic near its junction with the acoustic ganglion. The section passes through the endolymphatic sac, the crus commune and the lateral semicircular canal. It shows the intimate relation existing between the endolymphatic sac with the chorioidal membrane.

Labyrinth IV: (figures 7 and 8). Figure 7 is taken from Series $\mathrm{X} 11 \mathrm{~B}$, slide 3 , row 1 , section 5 . This section was selected because it shows the characteristic protrusion of the lagena on the ventromedian wall. The section is toward the caudal end of the labyrinth and passes through, besides the lagena and large vestibule, the posterior canal and the bulging caudal edge of the lateral canal. Sections a little in front of this show the lateral canal opening into the vestibule. Evidently in the process of transplanting this vesicle some injury was inflicted on the cells that were to form the middle part of the median surface. The resultant defect includes the absence of the endolymphatic appendage and a marked imperfection in the crus commune. Otherwise the general form of the labyrinth is quite perfect, as can be seen in figure 8.

Labyrinth $V$ : (figures 9 and 10). Figure 9 is taken from Series $\mathrm{X} 1 \mathrm{~B}$, slide 2 , row 3 , section 5 . The section passes through the endolymphatic sac, the short crus commune, and the lateral canal. The lateral vestibular wall is thin and distended and represents the dropsical type, which is a common deformity. There is a large acoustic ganglion connected centrally with the brain. This section shows well the relation between the endolymphatic sac and the chorioidal membrane. In figure 10 the shading of the lateral vestibular wall makes it look thinner than shown in the model and does not give the swollen appearance it 

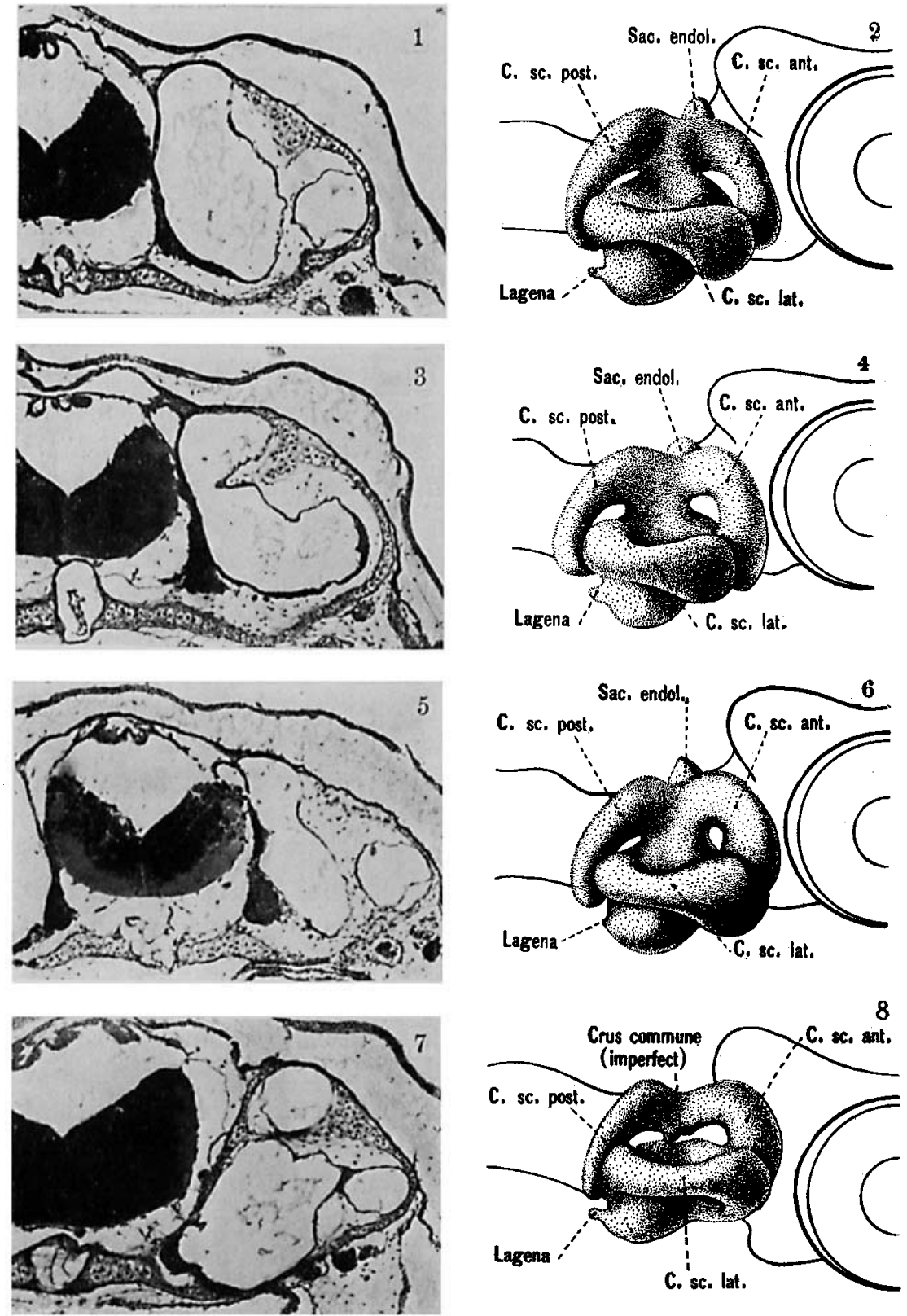
ought to have. The lateral wall in reality presses directly against the lateral canal. Aside from this dropsical tendency the general form of the labyrinth is quite normal. There is some deficiency in the cartilaginous capsule, particularly in the lateral center.

Labyrinth VI: (figures 11 and 12). Figure 11 is taken from Series X 4 A, slide 7, row 1, section 4. This section passes through the endolymphatic sac, crus commune, vestibule with its thickened macula acustica, and the lateral canal. The endolymphatic sac comes in contact with the chorioidal membrane in sections oral to this. Both histologically and in its general form this labyrinth is quite perfect. Figure 11 is the only photograph in the series that was retouched in any way. Here the negative was scratched to show the outlines of the lateral canal and lateral wall of the vestibule more distinctly.

Labyrinth VII: (figures 13 and 14). Figure 13 is taken from Series X 7 B, slide 6, row 3, section 3. The section passes through the endolymphatic sac, the crus commune, and the combined vestibule and lateral canal. The lateral canal exists only as a lateral pouch from the general vestibular cavity. A partial separation is indicated by an indentation on its dorsal surface, as can be seen in figure 14. The indentation does not completely perforate the pouch, so the canal is incomplete. There seems to be a general defect of the caudal portion of the labyrinth. So that, in addition to the imperfect lateral canal, the lagena is absent and the posterior canal small though otherwise complete. The acoustic ganglion is large (figure 13) and has a well developed root connecting it with the brain. The endolymphatic sac presents the usual relation to the chorioidal membrane.

Labyrinth VIII: (figures 15 and 16). The photograph shown in figure 15 is taken from Series X 2 B, slide 5, row 1, section 2 . In the process of embedding and mounting this series, some of the sections were injured, though not enough to interfere with the identification of the different parts. Thus it can be plainly seen that figure 15 passes through the endolymphatic appendage, the crus commune, the vestibular pouch, and the lateral canal. The anterior half of the labyrinth is quite perfect, as can be seen in 

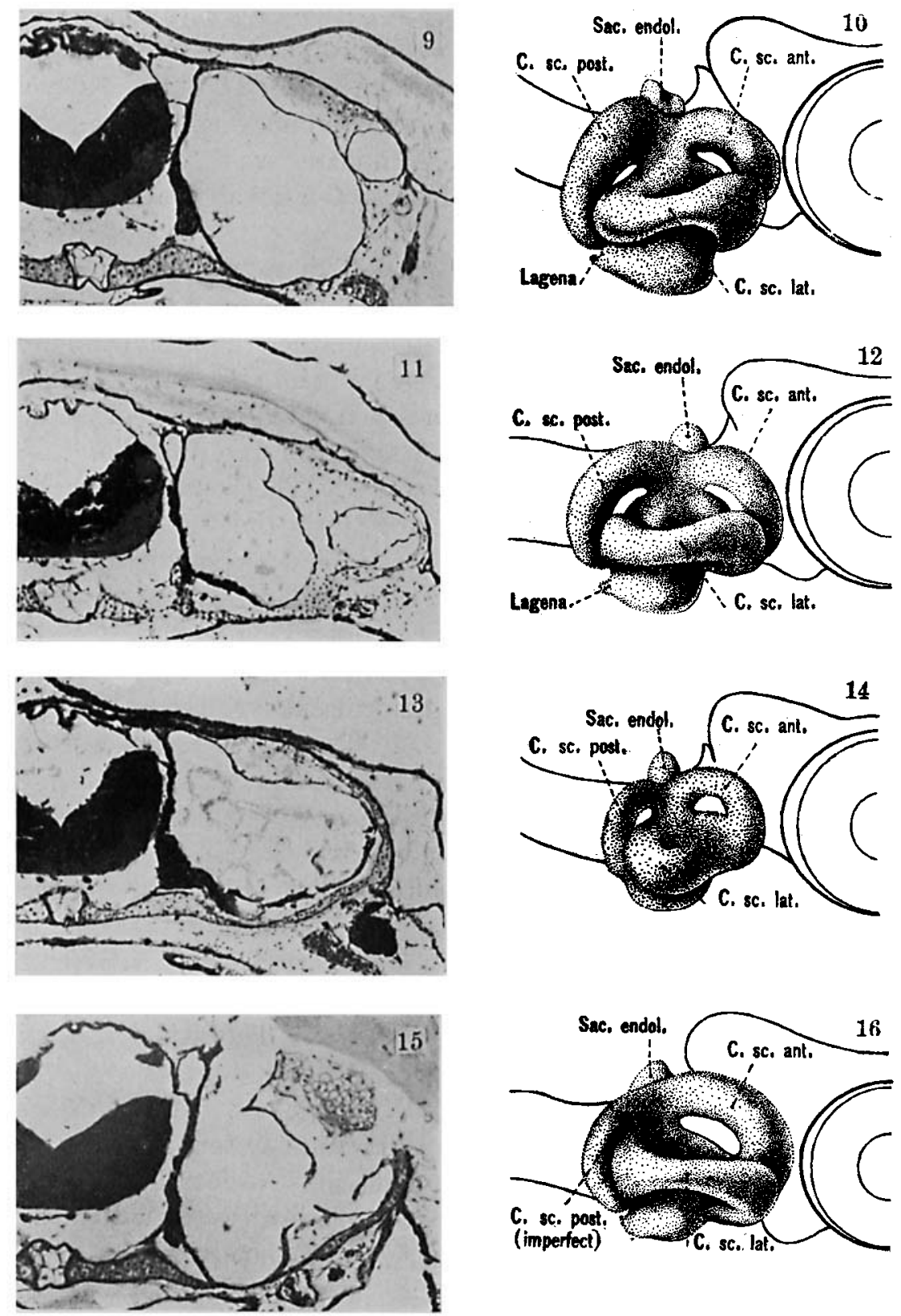
figure 16. The posterior region is defective in that the posterior canal and crus commune consist of a common pouch, taking however the usual shape of the posterior canal. The lagena developed as a pair of short pockets, one extending medially and the other caudally. Apparently the anlage was divided. The endolymphatic sac (figure 15) presents the usual relation to the chorioidal membrane.

Labyrinth IX: (figures 17 and 18). The photograph shown in figure 17 is taken from Series X 8 A, slide 2, row 4, section 9. It passes through the endolymphatic sac, the crus commune, and the vestibule with the lateral canal opening into it. In the sections oral to this the lateral canal becomes completely separated, though it is small and is deficient in the region of the ampulla. The anterior canal is small but well formed. The posterior canal is completely formed but lies closely against the vestibular wall. The vestibule is small throughout and lacks the lagena. The acoustic ganglion is well developed and is connected with the brain in the normal way. The endolymphatic sac (fig. 17) bears the usual relation to the chorioidal membrane. This is the first of what we have grouped as abnormal labyrinths.

Labyrinth $X$ : (figures 19 and 20). The photograph shown in figure 19 is taken from Series X $11 \mathrm{C}$, slide 1, row 2, section 8 . In this labyrinth the injury involves the endolymphatic appendage and the anterior canal. The latter exists as a blind pouch extending orally from the crus commune. This should be compared with figures 26 and 28 , where a similar defect involves the posterior canal. The remainder of the labyrinth is quite perfect. Figure 19 shows the crus commune, the vestibule, with a portion of the acoustic ganglion, and the lateral canal. The endolymphatic appendage is entirely absent.

Labyrinth XI: (figures 21 and 22). The photograph shown in figure 21 is taken from Series $X 8 \mathrm{~B}$, slide 2, row 2, section 8 . Here there is considerable abnormality in the ventral half of the labyrinth, and the labyrinth is correspondingly reduced in size. The anterior and posterior canals and the endolymphatic sac are fairly normal. In figure 21 can be seen the endolymphatic sac with its usual relation to the chorioidal membrane. The 

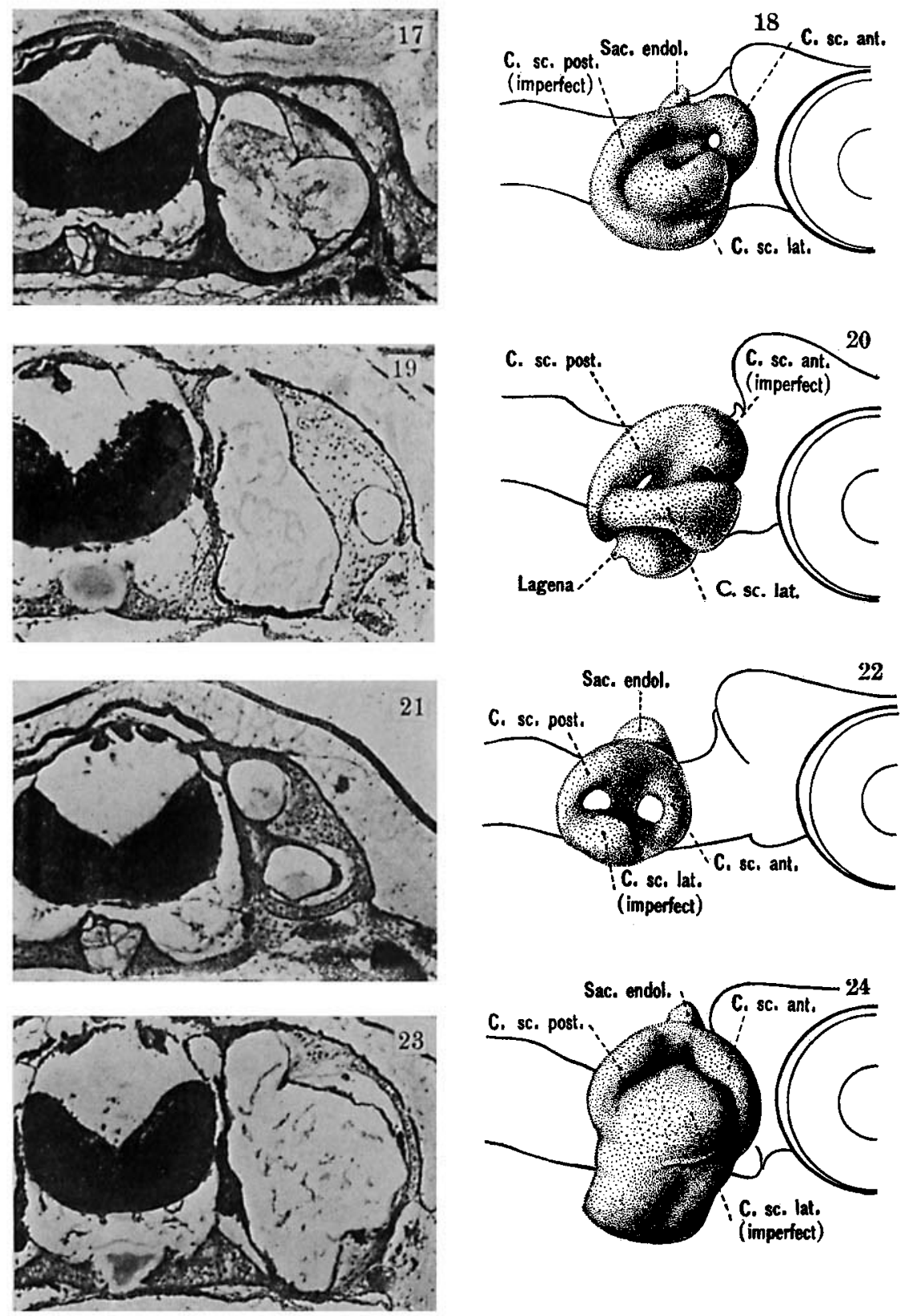
section also passes through the anterior canal just oral to the crus commune and through the vestibular pouch. The latter is much reduced in size. It possesses a macula with a diminutive nerve and ganglion, but the lagena is absent. The lateral canal exists as a lateral pouch projecting from the vestibule (fig. 22). In spite of the abnormal shape due to the deficient vestibule the planes of the anterior and posterior canals intersect at the usual angle.

Labyrinth XII: (figures 23 and 24). The photograph shown in figure 23 is taken from Series X $7 \mathrm{C}$, slide 2, row 3 , section 8 . The section passes through the endolymphatic sac, the crus commune, the vestibule with the large pouch extending laterally from it and representing the lateral canal. The endolymphatic sac bears the usual relation to the chorioidal membrane. The anterior and posterior canals are fairly normal. The vestibule is enlarged and irregular, and illustrates the dropsical type. It possesses the usual macula with nerve and ganglion (fig. 23). The lagena is absent.

Labyrinth XIII: (figures 25 and 26). The photograph shown in figure 25 is taken from Series X 4 C, slide 1 , row 3 , section 5 . It passes through the crus commune, the vestibule with its thickened floor, and through the lateral canal just being pinched off from the vestibule. Slightly oral to this the separation becomes complete. On examination of the reconstruction of this labyrinth (fig. 26) it can be seen that the chief injury involves the dorsal part of the labyrinth, and as a result the whole labyrinth is undersized. The greatest defect is in the posterior canal, which is represented by a bud extending caudally from the crus commune. A similar one is seen in figure 28 and the same kind of defect in an anterior canal has already been seen in figure 20 . The crus commune and the anterior canal are small though complete. The involvment of the median surface is shown by the absence of the endolymphatic appendage and the lagena.

Labyrinth XIV: (figures 27 and 28). The photograph shown in figure 27 is taken from Series $\mathrm{X} 6$, slide 1 , row 4 , section 2 . This labyrinth is of the dropsical or vesicular type. It is possible to recognize its general position but aside from the fairly 

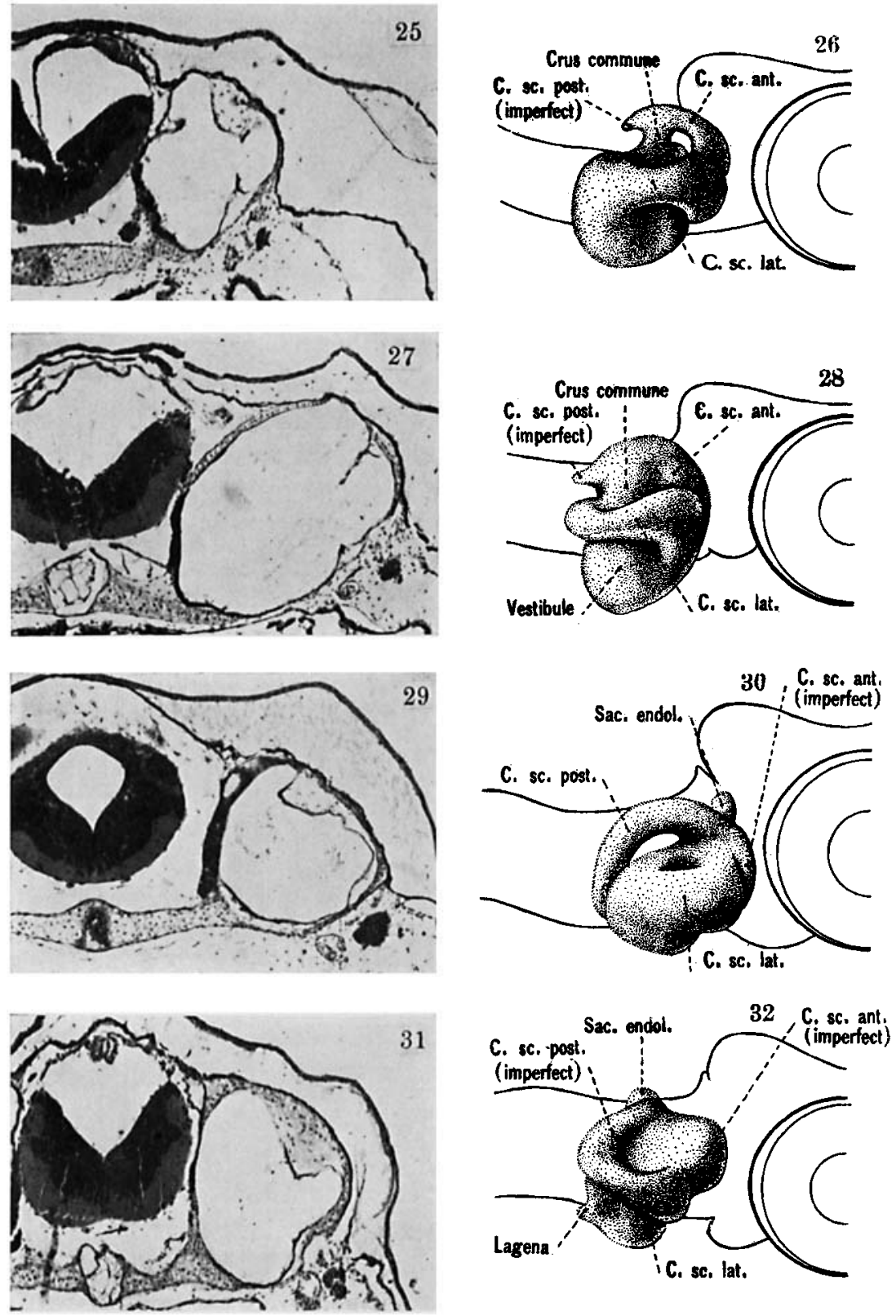

THE JOURYAL OF EXPERIMENTAI ZOÖLOGY, VOL, 16 , No: 1 
normal lateral canal it is poorly differentiated (fig. 28). In this kind of a labyrinth after undergoing differentiation for a short time the process ceases. After that the only further sign of development is an increase in size, which thus produces the dropsical appearance, such as is seen in figure 27 . The section is cut obliquely through the oral end of the lateral canal and the anterior canal. This section was chosen because it shows the macula and its nerve ganglion connection with the brain. The anterior canal, like the crus commune, is only slightly separated from the general vestibular cavity. The posterior canal is represented by a bud extending caudally from the region of the crus commune, such as we have already seen in figures 20 and 26 . There is no definite sign of a lagena or endolymphatic appendage.

Labyrinth XV: (figures 29 and 30). The photograph shown in figure 29 is taken from Series X 1 A, slide 6, row 3, section 8 . It passes through the oral end of the labyrinth, showing the endolymphatic sac, the small anterior canal, and the oral end of the lateral canal opening widely into the vestibule. As can be seen in figure 30 , the caudal part of this labyrinth is fairly normal. The oral end is quite imperfect, the parts being small and not properly differentiated. The anterior canal is only a pouch not completely separated from the vestibule. The lateral canal has a deep impression on its dorsal surface marking the beginning of a separation. This labyrinth has not completely recovered its normal posture. It is displaced forwards and is tilted partially forward so that the endolymphatic sac, instead of bearing the usual relation to the chorioidal membrane, is opposite the midbrain and lies embedded in the proötic ganglion. Though considering its abnormal shape it is not far from having the normal posture.

Labyrinth XVI: (figures 31 and 32). The photograph shown in figure 31 is taken from Series X 4 B, slide 2, row 2, section 4 . The section passes through the endolymphatic sac, which in the sections a little more caudal touches the chorioidal membrane in the characteristic way. The section also passes through the crus commune and the vestibule with the lateral canal opening into it. The lateral canal is quite perfect, but the anterior and poste- 
rior canals are only represented by pouches opening out of the vestibule in common with the crus commune. The shape of the pouches is relatively normal, and they are only deficient in not being pinched off from the vestibule. The lagena is quite normal. The acoustic nerve and ganglion are diminutive.

Labyrinth XVII: (figures 33 and 34). The photograph shown in figure 33 is taken from Series X $3 \mathrm{~A}$, slide 2, row 3, section 13. Due to some mechanical or other injury the last three labyrinths in our series are quite imperfect, and from examination of the sections alone (figs. 33, 35 and 37) one would be quite unable to orient them. The reconstructions are of great assistance in this respect. The section taken from Labyrinth XVII was selected because it shows the 'labyrinth fragment' which evidently was a portion of the main vesicle that became detached and developed as a separate little sac (fig. 34, x). In figure 33 it can be seen outside the cartilaginous capsule, partially covered by a cartilaginous coat of its own. It is not connected either by nerve or duct with the main labyrinth. It is possible that in the course of the operation a fragment from the native vesicle was left in the operation-pocket, and eventually formed this structure. Examination of the reconstruction shows that there is an interruption in the lateral canal, its two ends being sealed off. One never finds an open end in these imperfect labyrinths, they are always sealed off. The anterior canal is small but well formed. The posterior canal with the crus commune from a common pouch communicating with the vestibule. The vestibule has a normal macula with diminutive nerve and ganglion. There is no lagena and no endolymphatic appendage.

Labyrinth XVIII: (figures 35 and 36). The photograph shown in figure 35 was taken from Series X $3 \mathrm{~B}$, slide 2 , row 1 , section 11 . The whole oral region through which this section passes is of the dropsical type. The caudal region is not so pathological. The posterior canal, though incompletely separated from the vestibule and the crus commune, is otherwise well formed. The caudal half of the lateral canal is fairly normal, but the oral portion is distended like the rest of this portion of the labyrinth. Ventrally in one region this large labyrinth bulges through the parabasal 

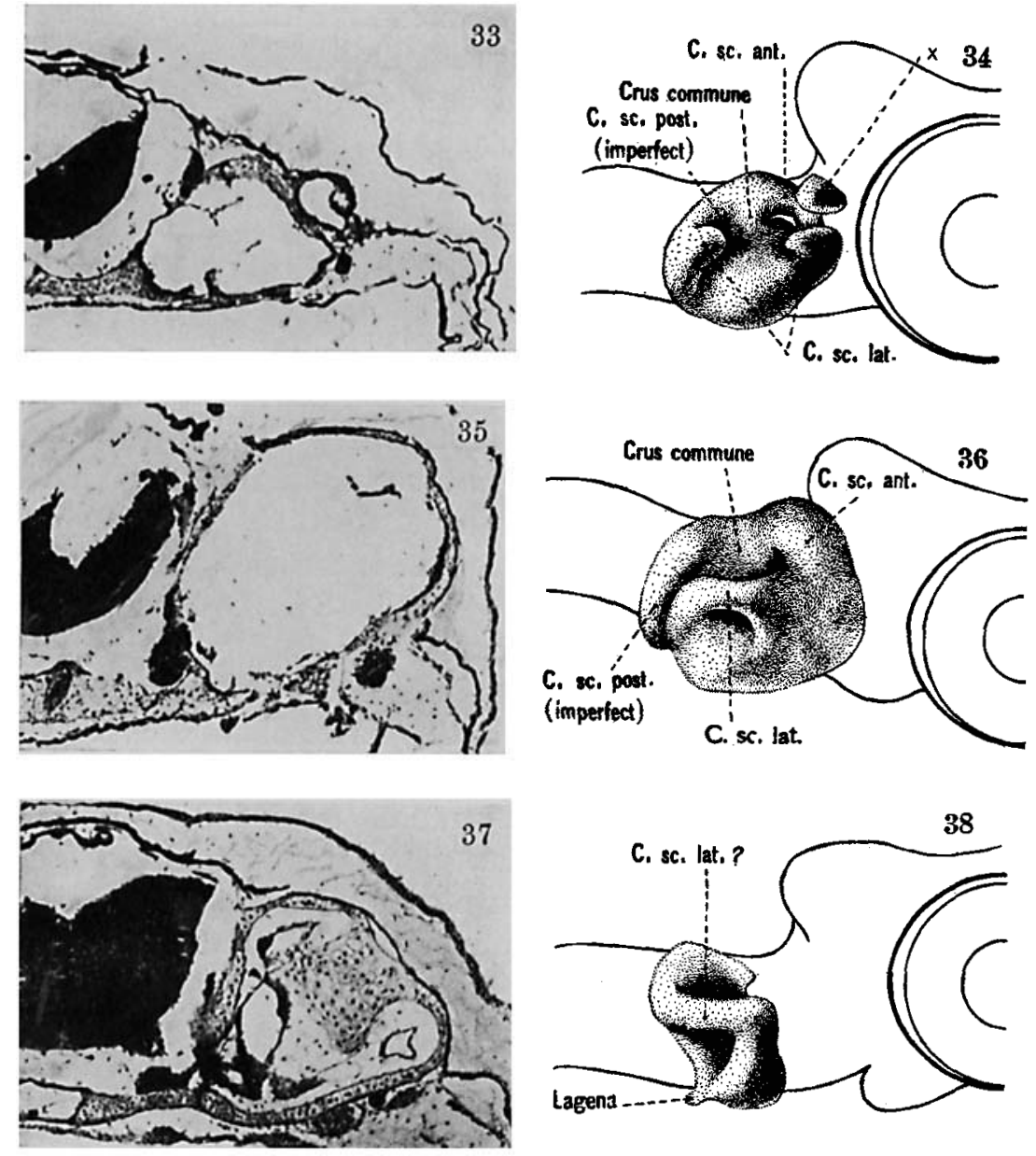

plate and protrudes in the pharynx. On the lateral surface of the anterior canal there is a deep pit indicating the usual site at which it is pinched off from the vestibule and crus commune, otherwise the separation is lacking. The presence of a lagena is questionable, and the endolymphatic appendage is entirely lacking. This, like Labyrinth XVII, through quite abnormal, can be fairly definitely oriented.

Labyrinth XIX: (figures 37 and 38). The photograph shown in figure 37 was taken from Series X $11 \mathrm{~A}$, slide 2, row 2 , section 2 . 
This is the last and most imperfect labyrinth in our series. It must be regarded as only a fragment. Apparently there is a lagena with the characteristic finer structure, shape and position. There is also a canal that corresponds in form and position to the lateral canal. Otherwise the different parts cannot be very well differentiated. This labyrinth is included in spite of its fragmentary character because it shows that even such an imperfect labyrinth is apparently affected in its posture by the influences interacting between it and its environments.

In a summary of the first eighteen of these experiments the result that concerns us most is that in all instances where the transplanted labyrinth had developed with sufficient completeness for identification of its various parts it was found that it had almost perfectly regained its normal posture. It was this fact that formed the chief object of our investigation, but we may add the following concerning the resultant abnormalities produced by the manipulation of the vesicle at the time of the operation.

a. In 8 out of 18 experiments there developed a practically normal labyrinth;

$b$. Where a defect occurs following the operation it is usually localized in some particular region of the labyrinth; it may be confined to the anterior, posterior, or median portion, while the remainder of the labyrinth is quite perfect;

$c$. The three different canals are defective with about equal frequency ( 30 per cent), though in an individual labyrinth where the canals are involved the imperfection is not distributed among them equally; and the planes of the canals, whether they are defective or not, are usually normal;

$d$. Defects of the endolymphatic appendage occur with about the same frequency as those of the canals;

$e$. The lagena is imperfect more often than any other part (in 8 out of 18 cases);

$f$. The acoustic nerve and ganglion were always present, though in a few cases quite diminutive; the connection of the nerve with the brain wall can almost always be recognized. 


\section{DISCUSSION}

The results that have just been recorded seem to show conclusively that there exists some influence between the transplanted ear vesicle and its environment that tends to control its posture, and that an inverted vesicle is thereby rotated back into the normal position. At the same time we must recognize the fact that Spemann ('10), from investigations of the same problem with experiments of much the same character, came to quite different conclusions. On examining and comparing our results, however, it will be seen that they are not necessarily contradictory, as thought by Spemann, but may perhaps be better described as differing in degree.

Including those in the present paper I have now reported 36 experiments in which the posture of the ear vesicle was especially studied. In 12 of these the ear vesicle had been rotated 180 degrees from its normal position; in $\mathbf{5}$ of them the ear vesicle had been transplanted without special placement; and in 19 of them the ear vesicle was transplanted and at the same time placed in a definite abnormal posture. In all of these 36 cases the labyrinth regained its normal posture. In Spemann's twelve reported cases in which there had been simple inversion of the ear vesicle, nine of the ear vesicles remained inverted, while two partially and one completely regained their normal posture. The latter Spemann regarded as an unsuccessful operation, surmising that it had slipped back into position directly after the operation. The fact of 'slipping' into the right position is the point of the whole matter. It is the remarkable fact that an ear vesicle, though rotated or turned or transplanted in an extremely abnormal position, nevertheless 'slips' into the correct position, that I am trying to establish in this paper.

It is of interest to examine Spemann's methods in search of some explanation for the difference in our results. For his experiments he used Rana esculanta larvae while I used Rana pipiens. It is not likely, however, that this would account for the difference in our results. His operations were performed at the time the ear vesicle is in the process of detaching itself from 
the deeper layer of the epidermis. This is the same stage used by me. However, in the technique of the operation our methods are different. Spemann raises a relatively large quadrilateral flap of skin, thereby exposing the ear vesicle, which he loosens and inverts so that the anlage of the ductus endolymphaticus points downward. He then replaces the skin flap and secures it in position by a weight, consisting of a slightly curved strip of cover glass. There are two factors here that may account for the difference in our results. In the first place Spemann, by reflecting a large skin flap, exposes a larger area of the deeper structures and perhaps thereby injures the environment in a way that lessens the postural interaction between it and the ear vesicle. It will be remembered in my operations there was only a linear slit opened, which by the spreading of its edges was sufficient for the manipulation of the vesicle. In the second place the use of the weight, as is done by Spemann, to hold the skin flap in apposition may retard the movement of the vesicle and prevent its rotation. From the nature of my wound no weight was necessary.

In addition it may be mentioned that Spemann always placed his vesicles so that the median or convex side remained toward the brain, while in most of my experiments it was made to point lateralward toward the skin. In this respect the displacement of the ear vesicle in my cases was more extreme than in Spemann's, making it all the more difficult for my vesicles to obtain a normal posture. Furthermore, in Spemann's experiments the ear vesicles were replaced in their own original pocket, while in all of my last series they were transplanted to another specimen, here again adding to the difficulty of their postural adjustment. In all other respects there seems to be no essential difference in our methods.

Judging from my own experiments there certainly exists a decided tendency between the ear vesicle and its environment that serves to control the posture, though we know from Spemann's experience that under certain circumstances this tendency is interfered with and the necessary corrective rotation is not accomplished. 
The development of a normally placed labyrinth from an inverted vesicle can only occur in one of two ways. Either the ear vesicle at the time of operation consists of indifferent cells which are capable of forming various parts of the labyrinth in accordance with how they chance to lie ('harmonisch-äquipotentielles System'); or the ear vesicle itself rotates as a whole after the operation, so that the cells originally intended for the different parts are brought to lie in their correct relation, where they continue in the fulfillment of their destined development. As was clearly argued by Spemann '10, it cannot be explained by the former. All our evidence points to a high degree of differentiation of the cells of the vesicle, and it is conspicuously proven by their possession of laterality, which has been described in the earlier part of this paper. We could not otherwise have a leftsided labyrinth on the right side of the head.

This leaves us with the alternative that the displaced ear vesicle does not stay in the position in which it is placed, but rotates into a normal posture. Regarding the nature of the force that produces the rotation there is yet little information. One must take into consideration at least three possibilities which either separately or in combination may explain its action. In the first place, it may be an active phenomenon on the part of the ear vesicle, that is, intrinsic motility of the vesicle itself; secondly, it may be based upon some attraction existing between some portion of the vesicle and the brain or other structure; and thirdly, there may be some purely mechanical basis for it.

In the first place, regarding the intrinsic motility of the ear vesicle itself, we are familiar with the flowing motion of protoplasm in the case of amoebal pseudopods, and Harrison ('10) has described the remarkable movements of the protoplasmic processes of nerve cells. In these instances there is a movement of one part of a single cell in relation to the rest of the cell. In the case of the ear vesicle, however, we should have to consider a massmovement of a group of cells. Such movements have already been described for small masses of cells, such, for example, as the lateral line rudiment, which, as has been shown by Harrison ('03) migrates in the course of a few days, all the way from the head 
region to the tip of the tail. Perhaps of a similar character is the shifting of groups of ganglion cells within the central nervous system as described by Kappers ('08) and the author (Streeter '08). These, however, are movements of small clusters of cells.

An example of intrinsic motility of a larger epithelial mass, which will be more analogous to the ear vesicle that we are dealing with, is afforded in the healing of skin wounds of young larvae. The epithelial coat, in such cases, spreads like an elastic sheet from the surrounding area over the wound. This mass-like movement of the epithelial coat is very characteristic. On watching the healing of a denuded area one can see the pigmented epithelial layer gradually spread in from all sides of the wound, covering in, as it does so, the exposed mesodermal elements, until eventually its edges tightly pucker together at the center. This is accomplished not by the formation of new epithelial cells but by the stretching out of the cells already there, as can be plainly seen by the alteration of the pigment pattern. The marked tension on the adjacent epithelium resulting from this movement in the region of the wound is strikingly shown by the way in which the pigment line existing along the dorsal crest of the larva becomes deviated toward the operated side. In such cases the epithelium belonging, we will say, to the left side of the body, is drawn well over to the right side, thus indirectly aiding in the covering of the seat of operation. For an excellent description of the behavior of the epidermis in the healing of wounds in larval Necturus, the reader is referred to the paper of Eycleshymer ('07). If the epithelial ear vesicle can move and adjust itself to varying conditions in the same way that the skin epithelium moves and adjusts itself we could then understand the rotation of the vesicles recorded in our experiments.

A second possibility is that the nerve and ganglion mass may serve to draw the vesicle into its proper position. At the time of the operation some of the ganglion element is usually transplanted with the vesicle, and as the latter develops we find the ganglion closely attached to the thickened part of its floor which is to form the macula. At the same time fibers have grown out from the central end of the ganglion to attach themselves to the 
side of the brain wall. This tendency to an early nerve-ganglion connection between the ear vesicle and some portion of the brain wall is evident even when the vesicle is transplanted in a strange environment such as in front of the eye (Streeter '06). The nerve seeks the brain wall, and is it conceivable that after it is securely attached it would act as a check or guy rope on the vesicle. With the subsequent growth and the change in the relative positions of the different structures, the nerve attachment would pull on it and, depending on its previous position, would tend to rotate it one way or another. When the vesicle is in front of the eye there are so many abnormal factors present that one could not expect a successful correction of posture through this means. But in the auditory region where other things are favorable it is conceivable that the nerve attachment might at least help in the adjustment of the position of the vesicle. As a modification of this idea it is conceivable that there exists some mutual attraction between the macula, ganglion, and brain wall which tends to draw them together by some psysico-chemical process. This would result in the same effect on the labyrinth as a whole as a tension of the acoustic nerve, and would serve in the same way as an assisting force in the adjustment of the position of the vesicle. In an analogous way it is possible that the endolymphatic appendage may be attracted to the side of the brain wall and thus tend to draw the vesicle into position. Wherever the endolymphatic duct and sac are well formed there exists a constant relation between them and the brain which I have never heretofore seen mentioned. The endolymphatic sac always lies closely applied to the membranous roof of the fourth ventricle near the rhombic lip. Some force may bring these two structures together, and thus we would have a secondary correcting influence on the posture of the whole vesicle. This, it must be admitted, cannot be the whole explanation, as we have vesicles with correct posture in cases where the endolymphatic sac is entirely absent.

As a third possibility there is to be considered, from a purely mechanical standpoint, the shape of the vesicle and the bed or pocket in which it fits. The auditory pocket is bounded on the median side by the relatively firm brain wall, ventrally by the 
developing cartilaginous skeleton, laterally and dorsally by the non-resisting auditory capsule and skin. In front of the proötic ganglion mass and the optic vesicle, and caudally the vago-glossopharyngeal complex. These different structures present different degrees of resisting pressure, and thus from different directions there are these compression forces acting upon the ear vesicle, to which, when normally placed, it is properly adjusted by its shape and the firmness of its different parts. Normally there is an equilibrium between the compression forces of the environment and the resisting forces of the vesicle. When the vesicle is abnormally placed there is a disturbance in this equilibrium which continues until the vesicle regains its normal position. Thus we would have the mechanical tendency for the disturbed vesicle to fit itself into the right position. An objection to this explanation immediately suggests itself, and that is the fact that vesicles having an abnormal form, and that could not possibly fit well in the usual pocket, notwithstanding, right themselves almost as well as the normally shaped ones. As another mechanical factor one might think of gravity. It is well known that gravity constitutes a decisive factor in certain embrylogical processes. Hertwig ('99) and Wetzel ('04) experimentally produced deviation from the normal development of the egg by alterations in gravity through the use of a centrifugal machine. It is true that gravity controls the position within the egg membranes of the amphian larvae in the early stages. The ventral side, due to the yolk mass, is heavier and is always down. In the case of the ear vesicle the large macula in its floor is thicker and presumably heavier than the other portions of the vesicle wall, and we might assume this fact as the reason that we always find the macula towards the ventral side and thereby a factor in the posture of the vesicle as a whole. However, when the larvae are removed from the membranes, as is necessary for purposes of operation, the conditions are quite altered. Being no longer supported by a gelatinous sphere which is easily kept properly erect by gravity, the larvae fall to the bottom of the dish and rest on their side, and we immediately have an abnormal direction of gravity, which persists throughout the critical period in the development of the ear ves- 
icle. If gravity were the controlling factor all of the ear vesicles in larvae removed from their membranes would be obliquely placed, whether operated upon or not. This we know does not occur, and therefore we may safely assume that gravity does not exercise any great influence on the posture of the ear vesicle.

\section{LITERATURE CITED}

Eycleshymer, A. C. 1907 The closing of wounds in larval Necturus. Amer. Jour. Anat., vol. 7.

HARRISON, R. G. 1903 Experimentelle Untersuchungen über die Entwicklung der Sinnesorgane der Seitenlinie bei den Amphibien. Arch. f. mikr. Anat., Bd. 63.

1910 The outgrowth of the nerve fiber as a mode of protoplasmic movement. Jour. Exp. Zoöl., vol. 9.

Hertwig, O. 1899 Ueber einige durch Centrifugalkraft in der Entwicklung des Froscheies hervorgerufene Veränderungen. Arch. f. Mikr. Anat., Bd. 53

KAPPERs, C. U. A. 1908 Weitere Mitteilungen ueber Neurobiotaxis. Folia Neuro-Biologica, Bd. 1.

LewIs, W. H. 1907 On the origin and differentiation of the otic vesicle in amphibian embryos. Anat. Rec., vol. 1. (Amer. Jour. Anat., vol. 7).

SpemanN, H. 1906 a ther eine neue Methode der embryonalen Transplantation. Verh. d. Deutsch. Zoöl. Gesell.,

$1906 \mathrm{~b}$ ṫber embryonale Transplantation. Verh. d. Gesell. Deutsch. Naturf. u. Arzte, 78 Vers., Stuttgart. 1910. Die entwicklung des invertierten Hörgrübchens zum Labyrinth. Areh. f. Entwick.-Mech., Bd. 30.

Streeter, G. L. 1906 Some experiments in the developing ear vesicle of the tadpole with relation to equilibration. Jour. Exp. Zoöl., vol. 3.

1907 Some factors in the development of the amphibian ear vesicle, and further experiments on equilibration. Jour. Exp. Zoöl., vol. 4.

1908 Nuclei of origin of the cranial nerves in the $10 \mathrm{~mm}$. human embryo. Anat. Rec., vol. 2.

1909 Experimental observations on the development of the amphibian ear vesicle. Anat. Rec., vol. 3.

Wetzel, G. 1904 Zentrifugierversuche an unbefruchteten Eiern von Rana fusca. Arch. f. mikr. Anat. u. Entwick., Bd. 63. 